\title{
A ENCICLOPÉDIA, O SABER E O SER DO MUNDO ${ }^{12}$
}

\author{
Sylvain Auroux
}

Pensar a unidade ou a totalidade do saber deve ser considerado como o problema mais fundamental da filosofia, ao menos desde Aristóteles ${ }^{3}$. Efetivamente, o estagirita concebia a filosofia como o discurso que se desencadeia/desenrola a partir dos princípios primeiros do conhecimento completo do cosmos. Em termos modernos, pode-se dizer que o problema filosófico essencial e primitivo é o da forma que a enciclopédia deve ter. Fora isso que Hegel compreendeu quando reuniu seu sistema sob o título de Enzyklopädie der philosophischen Wissenschaften [Enciclopédia das ciências filosóficas] (1817).

Se está claro que a filosofia desemboca na enciclopédia, parece menos evidente que toda forma de enciclopédia deva pressupor uma filosofia. Isso resulta particularmente do fato de a noçáo de enciclopédia ser uma noção moderna, nascida da imprensa para designar uma obra de compilação, um simples objeto técnico até certa medida. Raramente imaginamos que o real-do-objeto que é tal ou tal enciclopédia (alfabética, dividida em assuntos, em um ou em vinte volumes etc.) possa revestir um certo interesse intelectual. A obra de D’Alembert e Diderot é, assim, normalmente pensada como a expressão da ideologia de um clá (os "filósofos" ou os esclarecidos franceses), e sua forma é raramente tomada como o produto de uma filosofia. Talvez Hegel seja um dos únicos filósofos de envergadura que tenha ido ao encontro dessa tradição. Sabe-se que na Fenomenologia do espirito ele produz um longo comentário sobre o Aufklärung [Esclarecimento], baseando-se na oposição

1 Texto originalmente publicado em: AUROUX, Sylvain. I - L'Encyclopédie, le savoir et l'être du monde. In: AUROUX, Sylvain. Barbarie et Philosophie. Paris cedex 14, France: Presses Universitaires de France, 1990; p. 25-44.

Tradução de Phellipe Marcel da Silva Esteves.

2 Este capítulo é uma versão modificada de um artigo publicado sob o mesmo título no periódico Stanford French Review, em 1984. Evitamos ao máximo referências aos estudos relativos à filosofia de Diderot; recomendamos a leitura de J. \& A.-M. Chouillet, "Etat actuel des recherches sur Diderot" [Estado atual das pesquisas sobre Diderot], no periódico Dixhuitième siècle, n. 12, p. 443-470, 1980. 
entre a intelecção e a fé. $\mathrm{O}$ nó de argumentação consiste em mostrar que a intelecção pura é uma forma vazia, que não se reconhece em seu outro, e não alcança seu ser-por-si. Em homenagem aos mais bem-informados críticos, uma passagem célebre da obra serviria como comentário de $O$ sobrinho de Rameau, de Diderot; fala-se aí da cultura pura e da consciência rompida:

Nessa consciência calma não cai... nenhuma intelecção particular sobre o mundo da cultura. Ao contrário, esse mundo mesmo possui o sentimento mais doloroso e a intelecção mais verdadeira sobre si mesmo. $\mathrm{O}$ sentimento de ser a dissoluçáo de tudo o que se consolida, de ser esquartejado através de todos os momentos de seu ser-aí, de ter todos os seus ossos despedaçados; ele é também a linguagem de tal sentimento e o discurso cintilante do espírito que julga todos os aspectos de sua condição. A intelecção pura não pode, entáo, ter aqui nenhuma atividade nem conteúdo próprios. Sendo a linguagem dispersa, sendo o julgamento uma tagarelice espontânea que frequentemente se esquece e, não podendo constituir um todo senão por uma terceira consciência, isso não pode se distinguir como uma intelecção pura a náo ser reunindo esses traços dispersos em uma imagem universal e fazendo-lhe uma intelecçấo de todos ${ }^{4}$.

Hegel enxerga perfeitamente o problema da cultura moderna: a dispersão, ou ainda, a não interioridade de si de cada um dos momentos que a constituem. A questão a ser colocada aqui é a de saber se a totalização em si desse ser fora-de-si supóe uma operação ontológico-cognitiva que lhe faça, analogamente, uma totalização para si. J. Hyppolite (p. 94, n. 97, de sua tradução) propôs ver, na imagem universal que reuniria uma linguagem dispersa, uma alusão ao Dicionário filosófico de Voltaire. Todavia, se se trata de totalização, pode-se muito bem voltar à Encyclopédie. A enciclopédia é, entáo, não somente o problema essencial de toda filosofia, mas a tarefa específica que impóe à filosofia o estado do tecido cultural do Iluminismo e - sejamos francos - a dissolução de sua trama religiosa. Será Hegel mesmo quem cumprirá essa tarefa, de modo a fazer a filosofia regressar para aquém dessa dissolução: "O conceito absoluto é a categoria, ele significa que o saber e o objeto do saber são a mesma coisa” (ibidem, p. 99-100). Essa frase expressa mais ou menos o núcleo da filosofia hegeliana, sua ilusão totalitária e seu idealismo. Toda a epistemologia de Diderot (ele não vai pelo mesmo caminho que D’Alembert; voltaremos a isso no capítulo seguinte) ${ }^{5 *}$

4 Ver tradução francesa, por J. Hyppolite (Aubier-Montaigne, 1941), II. p. $93-94$ (ver notas do tradutor).

5* N.T.: Trata-se do capítulo "L'Illusion d'universalité" [A ilusão da universalidade], capítulo 2 do livro Barbarie et Philosophie. 
parece estruturada para refutar um sistema idêntico. $O$ saber é efetivamente disperso; mas não há lugar para unificá-lo em um ponto de acumulação mítico onde se concentraria a consciência de si, o Ser do objeto e seu saber. Contrariamente, a unificação do saber é possível ao deixá-lo a cargo da positividade de seu ser-sem-si. Isso porque, ao contrário do que sustenta Hegel, a intelecção - ou, se preferirmos, de modo mais claro: o racionalismo do Iluminismo - não é nem uma forma vazia nem uma consciência trágica. Ela é o plácido reconhecimento da originalidade inultrapassável do diverso e da força incontornável da positividade. A consciência totalizante (o filósofo que fala do saber) não se identificará jamais com a totalidade de seu objeto (o saber positivo) e, a fortiori, com o objeto desse objeto (o Ser do mundo). Sem dúvidas, é isso que Hegel abordará no Aufklärung. Toda a filosofia moderna, de resto, se une contra as Luzes francesas, o que se poderia chamar de preconceito de uma insuficiência filosófica fundamental. A tradição transcendental, que, contrariamente a Hegel, renuncia ao fundamento ontológico em benefício de uma analítica do Espírito, não pode mais aceitar ver o saber a cargo da positividade de seu ser-em-si. Isso seria (para ela) renunciar pura e simplesmente à filosofia em benefício do que considera como uma atitude lisamente naturalista. Acredito que seja inadequado aceitar, mais ou menos sub-repticiamente, o que funda tais críticas. Hoje em dia parece mais interessante e vital explicar os fundamentos de uma concepção que permita pensar a totalização do saber excluindo-se absolutamente o totalitarismo, sem supor a validade de uma problemática fundacional.

A Enciclopédia do saber supõe a totalidade não em si, mas como representação. É necessário que ela forneça a imagem do todo, mas ela não precisa ser toda. Para passar do todo à imagem do todo, é preciso, entretanto, um princípio que garanta a representação. Esse princípio não pode ser buscado senão sob a forma da representação, sob o ser representado ou sob a correspondência regulada entre os dois. Nenhuma dessas soluçôes é exclusiva, e todas elas foram utilizadas. Os tempos modernos foram variando sua ênfase sobre cada um dos elementos: o sujeito cognitivo em Descartes e Kant (a representação em si, portanto), o próprio Ser em Hegel, a harmonia pré-estabelecida, a visão em Deus ou a correspondência dos atributos divinos na obra dos sucessores de Descartes. De fato, não se podem desarticular os dois elementos que engajam os problemas essenciais da filosofia cognitiva. Se o Ser não tem unidade, ele não é um todo e, se ele não é um todo, é entáo necessário que seja a representaçấo que perfaça sua totalidade; mas, se ela é um todo, como é possível que o Ser não o seja? Uma simples sondagem nos escritos filosóficos de Diderot mostra que ele soube evitar esse dilema; 
isso porque, sem dúvidas, ele nunca produziu um sistema filosófico.

Diderot pensou e trabalho num clima de oposição à filosofia neocartesiana, cuja bússola intelectual é o Tratado dos sistemas (1749) de seu amigo Condillac. A filosofia neocartesiana é o mundo das hipóteses, aquele onde os carentes de sistematização, cobertos pelos farrapos da túnica de Sócrates, andam de muletas, e que, no sonho de Mangogul (Les Bijoux indiscrets, 1758, XXXII), desmoronam quando a experiência prevalece. "O tempo hoje inverteu quase todos os construtos da filosofia racional" (Da interpretação da natureza, 1754, XXI) ${ }^{6}$. O erro da "filosofia racional" (entendemo-la, assim como Diderot, como o cartesianismo, mas, em breve, tudo aquilo que a partir do século XIX passa a ser chamado de "racionalismo") foi o de preferir a representação ao Ser. Kant será perfeitamente consequente, já que proporá a ontologia inserida numa analítica do entendimento e sustentará que, em cem talos verdadeiros, não há nada mais que o pensamento em cem talos. Diderot, utilizando a mesma metáfora, havia denunciado a ilusão dessa posição: "um dos preconceitos da filosofia racional é que aquele que não souber contar suas moedas dificilmente será mas rico que aquele que tiver apenas uma moeda" (Da interpretação da natureza, XX). O essencial é obter moedas, melhor dizendo, acessar novos fatos. Diderot se coloca como o apologista da filosofia experimental: sua obra Da interpretação da natureza é o corolário disso. Tal qualificativo remete para dois filosofemas tradicionais: o empirismo e o método experimental, de que o autor diverge absolutamente. O empirismo (segundo a imagem abusiva construída pelo racionalismo) pretende tratar paralelamente o conteúdo do intelecto e a sensação, assim como a atividade cognitiva e os fatos. Se, para Diderot, não há nada mais a conhecer que o mundo, ele náo considera que a representação seja um espelho sereno dos fatos. É isso que, no Entretien entre d'Alembert et Diderot (1769), e depois no Rêve de d'Alembert, opóe Diderot a seu amigo. Ainda que seja sempre necessário fazer remissão ao mundo, a filosofia experimental é uma ação que ultrapassa o mundo. Podemos sonhar, propor hipóteses, sínteses grandiosas, mergulhar no "delírio filosófico" (Da interpretação da natureza, XXXIX). Ainda que não seja um racionalista, Diderot não é um empirista. Isso porque, analogamente, a filosofia experimental não se reduz à experimentação, ainda que ela por vezes adote seu esquema ("a observação coleta os fatos; a reflexão os combina; a experiência verifica os resultados da combinaçáo"). Ela se ocupa da existência, das qualidades e do emprego ( $D a$ interpretação da natureza, XV, XXXIV), e dá margem à "experiência mais

6 Todas as citaçóes feitas aqui remetem à edição Vernière, Euvres philosophiques (Garnier, 1964), exceto quando indicato diferentemente. 
extravagante". De um lado, o espírito não se esgota na sensação (ver ainda, na Réfutation suivie de l'ouvrage d'Helvétius intitulé l'Homme, de 1773, a recusa da máxima de que "sentir é julgar"); doutro lado, não há razão a priori que transcenda a experiência, tampouco método que dobre o mundo a suas normas. Trata-se de seguir "os movimentos e o andar de meu espírito" ( $D a$ interpretação da natureza, 0 ), e não de saber como nós formamos os silogismos e chegamos a conclusóes. A filosofia experimental é a experiênca do mundo, no sentido mais comum da palavra experiência: a vivência temporalizada de um espírito audacioso. Esse espírito, capaz de memória, não é nem um conteúdo nem uma forma: está mais para uma força ou uma energia. Portanto, não pode ir ao encontro do argumento de Arquimedes quanto à totalização unitária do saber.

Mas se o foco agora é o objeto da representação, o problema é indubitavelmente mais complicado. E, desde o início, tendo Diderot claramente consciência de seu desafio, ele o coloca em termos clássicos:

Se os fenômenos não são encadeados uns aos outros, não há motivo de a filosofia existir... se o estado dos seres está em uma vicissitude perpétua; se a natureza ainda está em operação, e apesar da cadeia que liga os fenômenos, não há motivo de a filosofia existir. Uma dúvida que talvez pudesse ser perdoada em vocês, ó, céticos, não é que o mundo tenha sido criado, mas que, sendo assim, ele tenha sido criado, mas que também será criado ( $D a$ interpretação da natureza, LVIII).

Em seguida, em relação à posição desse desafio, a soluçáo apontada parece sustentar, por sua vez, dois ramos de alternativa. Do lado positivo, é necessário ter em mente o monismo ontológico de Diderot, o que é chamado de seu materialismo ou de seu panvitalismo. O fato de que ele variou ou evoluiu diante dessas questóes não é lá muito relevante para a nossa proposta. $\mathrm{O}$ importante é que ele tenha constantemente procurado um princípio de unidade. Citaremos aqui um texto que, embora mais tímido do que o que se pode encontrar no Rêve de d'Alembert (falta-lhe abordar a vida), é de todo modo exemplar:

Admitir-se-á, na natureza, assim que a física experimental estiver mais avançada, que todos os fenômenos, sejam eles da gravidade, da elasticidade, da atraçáo, do magnetismo, da eletricidade, não passam de diferentes facetas da mesma afeição (Da interpretação da natureza, XLV).

O problema crucial surge quando se percebe que Diderot escolheu, incontestavelmente, o caminho que, a seus olhos (ver citação acima do $D a$ interpretação da natureza, LVIII), parecia condenar a filosofia. O Ser é todo 
tocado pela historicidade; o evolucionismo de Diderot, aquém de uma teoria biológica, é uma tese metafísica. Ele o conduz a construir uma concepção da natureza completamente original:

Eu chamaria de... elementos as diferentes matérias heterogêneas necessárias para a produção geral dos fenômenos da natureza; e eu chamaria de natureza o resultado geral vigente, ou os resultados gerais decorrentes da combinação dos elementos (Da interpretação da natureza, LVIII).

O mundo não é, então, como foi no passado ou como será no futuro. Ainda assim, é somente ele que garante o saber ("as noçôes devem ter um fundamento na natureza”, Da interpretação da natureza, VII). Diderot, entáo, só escapa do relativismo absoluto, que tornaria o saber impossível, por meio de um tipo de atomisto do elemento. Isso implica que não haveria forma a priori da totalidade natural. A natureza não é nem um princípio englobante nem de organização, é um resultado provisório. Não há, no ser do objeto do saber, princípio que seja ao mesmo tempo totalizante e unificador. Como vimos, Diderot coloca a existência de um princípio único e desconhecido na raiz dos fenômenos, mas ele não é constitutivo do Ser. $\mathrm{O}$ autor fala das "diferentes facetas da mesma afeição"; o Ser não é uma afeição, é uma substância. Essa substância é a matéria, mas ela não constitui o Ser senão por forma de "matérias heterogêneas". É por isso que o monismo materialista de Diderot não poderia oferecer à enciclopédia a lei de totalizaçáo que a constitui. Nossa proposta ficará mais clara com uma comparação com Spinoza. A substâcia, em Spinoza, é o princípio ontológico de unidade que não apenas sustenta a ordem do mundo, como também permite o ordenamento da enciclopédia (entendamos o plano da Ética); ela é anterior às afeiçóes, e a infinitude de seus atributos infinitos constitui sua essência. São tais afeiçôes da substância (seus modos) que constituem a diversidade das coisas do mundo. Spinoza faz prevalecerem o mesmo, o um, o todo e o infinito, em relação ao outro, ao múltiplo, ao parcial e ao finito. Diderot propóe abordagem inversa; os elementos, a finitude e a diferença são a raiz do Ser. O monismo materialista não consiste na posição de uma substância homogênea, onde as diferenciaçóes e as limitaçôes operariam. É o reencontro das diferenciaçóes que produz a identidade, e o idêntico pode variar ao infinito ("parece que a natureza se regozijou com a variação do mesmo mecanismo numa infinidade de maneiras diferentes", Da interpretação da natureza, XII). Pode-se comparar a posiçáo de Diderot à de Lucrécio. Trata-se da mesma diversidade no fundamento do Ser (no nível das imagens, os enxames de abelhas substituem a poeira esvoaçante contra os raios de sol), da mesma confiança nas leis da natureza, que, entretanto, não são nada 
além do produto variável dos elementos estáveis. Dito de outra maneira, parece-nos que, em Diderot, a unidade postulada no âmago dos fenômenos naturais em nada se afasta da heterogeneidade originária e da variabilidade do devir. É então impossível fundar ontologicamente, sub specie aeternitatis, a ordem do saber.

Haverá objeçôes: restariam, ainda, duas possibilidades. De um lado, pode-se conceder valor substancial ao devir (quero dizer, dar-lhe valor de substância, fazer dele o fundo do Ser); eis o caminho escolhido por Hegel. De outro, pode-se se apoiar sobre o criador do mundo. Há uma tese fundamental de Diderot que faz as duas possibilidades parecerem inadequadas: trata-se da recusa das causas finais. Como para Spinoza, elas não passam de ilusôes antropomórficas (Da interpretação da natureza, LVI). Sem causas finais, não se pode conceder valor substancial ao devir; como a natureza não tem fim, ela não tem um Ser concluído, e não há Saber Absoluto, ou seja, um saber capaz de transcender a dispersão de seus momentos, de tornar-se Espírito Absoluto, ideia eterna que se autoproduz. E isso nos leva ao problema de Deus. Em alguns de seus escritos, Diderot se mostra teísta, ou melhor, deísta ${ }^{7}$. Deus se mantém incompreensível, e, se ele é a ratio essendi do mundo, ele não pode ser sua ratio cognoscendi. Podemos seguir em frente tratando da Addition aux pensées philosophiques (1772). A ideia de Deus é a invenção de um hipocondríaco, que, para se vingar dos homens, imagina "à frente deles uma grande quimera a quem dáo mais importância que à sua propria vida, e com quem eles jamais poderiam se entender". Na ordem humana, a ideia de Deus perturba a comunicação que, de fato, é o elemento (o meio) do saber. O parágrafo seis do Da interpretação da natureza é uma reflexão sobre a infinitude do Ser e da totalidade do saber, que retoma o tema de Babel. Os filósofos têm o hábito, para estabelecer o conhecimento, de fazer dele uma entidade consubstancial ao Ser. Como o Ser verdadeiro é atemporal, a verdade é eterna. A categoria da eternidade não existe em Diderot. O que funciona em seu lugar é o infinito. O saber, como a natureza, é temporalizado. É por isso que se podem fazer conjecturas, apostar no futuro. Assim, a temporalidade do saber implica sua abertura. Os fenômenos da natureza são uma multidão infinita. Por si só, isso já desqualifica a imagem tradicional do livro do mundo. A natureza não é um livro escrito na língua dos matemáticos ou em nenhuma outra língua filosófica. Nossa língua filosófica

7 Cf. contra, Principes philosophiques sur la matière et le mouvement, 1770, publicado por Naigeon no artigo - Diderot - dos tomos da Encyclopédie méthodique, dedicada à filosofia. Lá lê-se: "- A suposição de um ser, qualquer que seja localizado fora do universo material é impossível”. 
jamais será completa e, o que é ainda mais grave, se ela fosse, ninguém conseguiria compreendê-la. A natureza, por ser infinita, transcenderá sempre o saber. A busca pelo edifício do saber tem algo de tolo, assim como a torre de Babel, e será bloqueada pela confusáo das línguas. Se o saber deve constituir uma totalidade, é necessário encontrar um princípio que o circunscreva, e que não possa suprir o Ser da natureza.

Um dos temas essenciais que os iluministas inauguraram na filosofia é o da incompletude do saber; é um tema que rejeitará o racionalismo kantiano e pós-kantiano desavisado (a coisa em si supóe uma outra problemática, já que o saber, sendo de natureza fenomênica e construído pelo sujeito, possui a vocaçáo, em sua ordem própria, de ser completo). Encontra-se novamente esse tema na obra de D'Alembert, no artigo "Elemens des sciences" [Elementos das ciências], redigido por ele para a Encyclopédie, onde o modelo cartesiano da cadeia das razóes, se continua a ser a forma ideal de totalização, só pode ser realizado localmente, sem expectativa de que as descontinuidades que impossibilitam ao saber coincidir com o Ser do mundo venham a substituir o modelo. Também se o encontra na obra de Condillac, particularmente em sua Lógica (1780). O abade distingue os conhecimentos que são completos (matemática e metafísica, no sentido como ele entende essa palavra, ou seja, a teoria do entendimento) dos que são incompletos, como a física. Nisso há uma análise muito profunda, porque ela não é limitada às consideraçóes sobre a verdade. Um conjunto de conhecimentos é completo se a todo fato corresponde um conhecimento; se a todo conhecimento corresponde um fato, ele é indubitavelmente exato, mas incompleto. Disso resulta que o destino da matemática e o da física são dissociados. Para Condillac, como para Diderot (ver Da interpretação da natureza, III: "La chose du mathématicien n'a pas plus d'existence dans la nature que celle du joueur" [O negócio da matemática não tem mais existência, na natureza, que o do apostador]), a questão do saber do mundo se relaciona à física ("sem contradição, ela é a base de nossos novos conhecimentos", Da interpretação da natureza, VI), e não à matemática, cuja certeza e completude se prendem ao fato de que elas são abstraçóes construídas pelo homem.

A incompletude do saber do mundo, por um lado, e o movimento temporal pelo qual o saber advém ao espírito humano, por outro, constituem os problemas essenciais para o empreendimento enciclopédico. Não se pode recorrer nem à totalidade fechada da enciclopédia medieval (speculum mundi) nem à totalidade aberta do discurso more geometrico. Diderot dá a esses problemas três tipos de resposta, de resto perfeitamente compatíveis. 
No Da interpretação da natureza, o filósofo estabelece um limite à extensão do saber: "O útil circunscreve tudo. Será o útil que, em alguns séculos, dará o limite à física experimental, como tem sido feito com a geometria” ( $\$$ VI). Esse limite tem um valor duplo. De um lado, ele fixa o saber em relação à infinitude de seus objetos possíveis: há um saber do mundo, incompleto mas suficiente. Doutro lado, ele fixa o saber em relação à sua extensão histórica. Uma das teses constantes de Diderot (pode-se encontrá-la no artigo "encyclopédie", da Encyclopédie (1775)) ${ }^{8}$ é que há pontos para além dos quais um dado ramo do saber não progride mais. Ele acredita que a matemática de sua época mal alcançou esse ponto. A conjectura se revelou errônea. Mas ela possui o mérito de questionar o desenvolvimento dos conhecimentos de modo original. A partir do momento em que o saber náo é mais concebido como um conjunto de verdades eternas ${ }^{9}$, seu crescimento potencial torna-se infinito. De modo que não se admite a possibilidade de que exista um sujeito suscetível de totalizar o infinito (Deus, ou o Espírito Absoluto hegeliano): ou o saber (acumulando sobretudo seu desenvolvimento temporal) torna-se rapidamente não matrizável, ou é necessário optar, num dado momento, pelo crescimento zero.

O artigo "encyclopédie" é publicado um ano depois do Da interpretação da natureza; o filósofo retoma a obra quanto ao problema da mobilidade e do crescimento dos conhecimentos. O ponto de vista é mais complexo. De um lado, Diderot se detém sobre inchaço da massa impressa que faz da enciclopédia uma necessidade. De outro, ele reflete sobre a mudança do saber (as revoluçôes) e suas consequências para o trabalho enciclopédico. A enciclopédia em si está situada no tempo, e triplamente. Primeiramente, por ela dever ser concluída num tempo finito. Em segundo lugar, por ela ter como objetivo resumir o saber alcançado antes dela. Em terceiro, por ela dever sustentar uma posição aceitável face ao futuro.

O modelo utilizado por Diderot para pensar a movência do saber é o da linguagem: "As opiniôes envelhecem e desaparecem como as palavras" (loc. cit., p. 182). Há, na linguagem e em seu uso, causas intrínsecas que fazem com que uma língua se afaste de sua origem, e com que ela cesse de

8 As citaçôes desse artigo são extraídas da edição das Euvres completes de Diderot (Hermann, 1975), VII.

9 "Vérité éternelle " [verdade eterna] é um termo ambíguo. Tomemos uma proposição p e as duas condiçôes seguintes: i) se $p$ é verdadeira a $t i$, entấo ela é verdadeira a quem quer que seja $t$; ii) se $p$ é conhecida como verdadeira a ti, entâo ela é cinhecida como verdadeira a quem quer que seja $t$. Não parece que Diderot recuse i); é a verdade eterna no sentido de ii) que é rejeitada. A verdade na obra de Diderot sempre possui uma modalidade epistêmica, é um conhecimento, e o processo cognitivo é temporal. 
poder ser compreendida. Novas noçóes surgem, assim como novas palavras, e elas precisam de novas palavras para surgirem. Nesse sentido, a enciclopédia pode estar antiquada, como uma linguagem dos séculos passados. Antiquada, ultrapassada por suas faltas, mas também pelo que desapareceu do universo intelectual. Essa concepção da mobilidade leva ao limite do relativismo; um limite que Diderot náo cruza:

Os conhecimentos náo se tornam nem podem se tornar comuns a não ser até certo ponto. A verdade é que se ignora qual é esse limite... as revoluçóes são necessárias; sempre houve e sempre haverá... Nas ciências em geral, há um ponto além do qual convencionou-se não passar. Assim que esse ponto é atingido, os monumentos restantes desse progresso nunca mais surpreendem a espécie inteira (loc. cit., p. 187).

Mais moderado que em Da interpretaçáo, Diderot não define o limite da evolução de uma disciplina; mas fala de sua existência. Isso acarreta em que as revoluçóes do saber náo resultam da incomensurabilidade dos saberes de diferentes épocas. Revolução, em sua obra, não tem mesmo o sentido que carregar hoje como na obra de T. Kuhn ${ }^{10}$. De resto, a enciclopédia seria uma atividade se náo incompreensível, ao menos insensata, numa problemática da ruptura epistemológica. Seu papel é transmitir os conhecimentos, escolhendo-os e resumindo-os. A transmissão dos conhecimentos ser uma tarefa é algo que supóe que esses conhecimentos não repousem eternamente no espírito do homem. Eles não são herdados biologicamente, mas passam de geraçáo em geração por tradição externa e submetidos aos riscos das civilizaçôes ${ }^{11}$. Isso não lhes remove em nada o núcleo de objetividade que eles mantêm por sua relação com os elementos naturais.

A segunda resposta de Diderot aos problemas da totalização do saber volta, então, a fazer o empreendimento enciclopédico imergir na própria

10 P. Swiggers, «Diderot on Revolution in Science : A Note ", The Philosophical Forum 13, $\mathrm{n}^{\circ} 4$ (1980), pp. 408-412, segue até afirmar que "Diderot conception of the evolution of science prefigures the Kuhnian model for the history-writing of science" [A concepção de Diretor de evolução da ciência prefigure o modelo kuhniano para a escrita da história da ciência]. Uma simples leitura da obra de Kuhn (The Structure of Scientific Revolutions [Chicago : Chicago University Press, 1962]), e do artigo "Encyclopédie" desqualifica esse tipo de aproximação, arbitrário e anacrônico.

11 Ver o artigo "encyclopédie”, p. 188: "Le moment le plus glorieux pour un ouvrage de cette nature, ce serait celui qui succéderait immédiatement à quelque grande révolution qui aurait suspendu le progrès des sciences, interrompu les travaux des arts, et replongé dans les ténèbres une portion de notre hemisphere" $[\mathrm{O}$ momento mais glorioso para uma obra dessa natureza seria o que sucede imediatamente alguma grande revolução que suspenderia o progresso das ciências, interromperia os trabalhos das artes, e ressubmergeria uma porção de nosso hemisfério nas trevas]. 
história do saber. Não há necessidade de transcender a historicidade, e o saber, em sua mobilidade, ultrapassa a enciclopédia inteira. Mas existem pontos de fixidez, de progresso alcançado, que fazem com que, em seu devir, o saber não se extingua num fluxo heraclitiano. Os pontos de fixidez certamente dependem da relação dos conhecimentos com o Ser do mundo (o erro é instável). Eles dependem igualmente do ponto de vista escolhido pelo enciclopedista: "Seja o universo real, seja inteligível, há uma infinitude de pontos de vista sob os quais ele pode ser representado, e o número de sistemas possíveis do conhecimento humano é tăo grande quanto o desses pontos de vista" (loc. cit., p. 211). Diderot decidiu e escolheu o ponto a partir do qual representar o saber:

É a presença do homem que faz com que a existênca dos seres seja interessante; e o que podemos propor de melhor na história desses seres que nos submetermos a essa consideração? Por que não introduzimos o homem na nossa obra como ele está localizado no universo? Por que não fazemos dele um centro comum? (loc. cit., p. 212).

Isso o Da interpretação respondia com o útil. O artigo "encyclopédie" responde com o homem: a solução é simplesmente mais geral. Já a encontrávamos na obra de Bacon. Aí, ela ela levou o filósofo inglês a escolher o sistema ptolomaico ao copernicano ${ }^{12}$. A concepção de Diderot é menos ingênua. Ela se distingue radicalmente de todo antropocentrismo, mas igualmente da filosofia do sujeito. A tese de Kant e a atitude de Diderot são conciliáveis, enquanto a filosofia de Koenigsberg póe limites ao conhecimento e os localiza na constituição do sujeito transcendental. Só que não existe sujeito transcendental na obra de Diderot; é o homem que é o centro de onde o mundo é conhecido, e a partir dele é razoável totalizar a representação incompleta do universo, não é nem um indivíduo nem uma racionalidade abstrata, suspensa pela eternidade num ponto fixo fora do mundo, é a humanidade concreta, que trabalha, goza e morre. Isso nos leva ao terceiro tipo de soluçáo, a nosso ver o mais fundamental, e que é largamente desenvolvido no artigo "encyclopédie". Umas das conclusóes da Lettre sur les aveugles [Carta sobre os cegos] (1749) é que há "casos em que o raciocínio e a experiência dos outros podem esclarecer a visão sobre a relaçáa do toque, e instruí-lo que, se vale para os olhos, vale para o tato"13. Há, nessas poucas linhas, mais que uma resposta ambígua ao problema de Molyneux. Em toda a análise de Diderot, encontra-se uma interrogaçáo subjacente sobre a possibilidade de construir

12 Novum Organum II, XXXVI; ver J. Chouillet, La formation des idées esthétiques de Diderot 1745-1763 (Colin, 1973). pp. 399-400.

13 In Euvres philosophiques, p. 145. 
uma representação do mundo que não aquela constituída pela concatenação habitual dos nossos cinco sentidos, ou de construir a mesma representação abstrata (por exemplo, a matemática) na ausência de um dos cinco sentidos. É a objetividade que está em questão aqui. Limitando nosso entendimento por nossa sensibilidade, admitindo que outros sentidos são possíveis, Kant questionará o mesmo; mas a subjetividade transcendental impede a possibilidade de outros homens possuírem outras visóes do mundo. $\mathrm{O}$ importante parágrafo $40 \mathrm{da}$ Crítica da faculdade do juizo, ao introduzir como máxima da reflexão o "pensar colocando-se no lugar de todo outro", baseia a comunicação universal na constituição da subjetividade. Sem trair Diderot, pode-se adiantar que sua visão é exatamente inversa: não é a estrutura da subjetividade que funda a intersubjetividade, é a comunicação que dá consistência e universalidade à representação individual. As Additions [Acréscimos] à Lettre sur les aveugles (1782), somadas ao caso de Mélanie de Salignac ("sua mãe lia história para ela, e era um ofício igualmente útil e agradável para ambas”) ${ }^{14}$, só fazem confirmar nossa leitura. A comunicação é o terceiro tipo de resposta proposto ao problema da totalizaçáo do saber; isso expóe que a linguagem mantém um lugar bem importante no artigo "encyclopédie".

A comunicação é o inverso da especialização. Diderot é partidário da especialização da competência limitada à parte do mundo que é familiar. Decorre disso que o tema do saber global é, antes de qualquer coisa, social; a enciclopédia não poderia ter um único autor ${ }^{15}$ :

Jamais executaremos um bom vocabulário sem o concurso de um grande número de talentos, uma vez que as definiçóes de nome quase não diferem das definiçôes de coisas e também porque as coisas não podem ser bem definidas ou descritas a não ser por aqueles que fizeram um longo estudo (art. encyc., p. 177).

A comunicação é, portanto, o meio da totalização; ela fornece imediatamente o meio em que a totalização deve se efetuar:

A língua de um povo fornece seu vocabulário, e o vocabulário é um quadro bem fiel de todos os conhecimentos desse povo. Cada ciência possui seu nome; cada noção na ciência também; tudo o que é conhecido na natureza é designado, assim como tudo o que foi inventado nas artes, e os fenômenos e os manuscritos e os instrumentos... A língua é um símbolo dessa multiplicidade de coisas heterogêneas (art. 'encyc.', p. 189-190).

Descobre-se assim que a ordem arbitrária com que o alfabeto organiza

14 In Euvres philosophiques, p. 164.

15 Ver os trabalhos de J. Proust e J. Lough sobre os colaboradores da Encyclopédie. 
as palavras de uma língua constitui a apresentação mais racional de uma enciclopédia ${ }^{16}$. Onde Kant náo reconheceria mais do que uma rapsódia, Diderot detecta a única ordem possível para os conhecimentos, legados à positividade de seu exercício pelos especialistas. Alguns refutariam que assim não seriam asseguradas nem a coerência do compêndio nem sua exaustividade. Essas duas questôes são resolvidas pelas remissóes entre os artigos; "parte mais importante da ordem enciclopédica". Rompendo a ordem unilinear do tratado para estabelecer a ordem multidimensional do dicionário alfabético, Diderot escapa da tarefa fastidiosa de enumerar, sem omissóes, os lugares do saber, e sobretudo do fechamento ilusório que dá a Kant a dedução transcendental das categorias. O sistema de remissóes, em sintonia com a hipótese de uma continuidade na ordem do $\operatorname{saber}^{17}$, assegura que o que a enciclopédia reúne será ao mesmo tempo suficiente e não supérfluo. Ela não conterá nada de supérfluo, porque "se uma palavra fosse tão isolada que não se fizesse menção a ela em parte alguma, fosse em discurso, fosse em remissão (...), ela poderia quase ser omitida sem grandes consequências" (loc. cit., p. 229). Ela será suficiente, por um lado, porque, por existir o mecanismo de remissão, isso permite restabelecer as omissóes; e, por outro, porque, para que uma coisa omitida não seja percebida, seria necessário que todas as suas remissôes sumissem, que toda uma ordem de seres fosse esquecida, "o que é metafisicamente impossível".

O golpe de mestre do filósofo consiste então em ter aceitado deixar o saber por si mesmo, a cargo de sua positividade e de sua prática. Isso significava destruir a ideia de um sistema filosófico, de uma metafísica capaz de dizer de uma vez por todas o segredo do mundo. A túnica de Sócrates, cujas sistemáticas compartilham os farrapos para esconder sua nudez, nunca será reconstituída. Ou melhor, a túnica é reconstituída pela correlação, pelo compêndio, pelo esforço de comunicaçáo que constitui o trabalho dos enciclopedistas. Esse trabalho não é neutro.

O crescimento dos conhecimentos, o volume de massa impressa e de especialistas de todas as espécies, inevitavelmente criou uma desordem no universo do saber. Poderíamos dizer que os progressos do espírito humano correspondem a um crescimento de entropia no mundo cultural. Diderot é,

16 Sobre todos esses problemas, ver a conclusão de S. Auroux no livro La sémiotique des encyclopédistes (Payot, 1979).

17 Art. "encyclopédie”, p. 229: "não há nada de existente na natureza ou no entendimento, nada de aplicado nas oficinas, que não possua um grande número de fios no sistema geral do conhecimento humano". 
sem dúvida, o primeiro filósofo a ter previsto o problema do conhecimento sob um aspecto moderno. Daí se pode ver a profundidade de sua injunção: "é preciso deixar a experiência livre" (Da interpretação da natureza, XVVIII), ou ainda sua escolha pelas experiências extravagantes, pelas aproximaçóes inesperadas $^{18}$. O liberalismo metodológico de Diderot não compartilha dos fundamentos éticos que encontramos hoje na obra de Feyerabend (ver Contra o método, 1975). Ele corresponde a uma abordagem epistemológica, que enxerga o saber como um objeto social, e não somente como a atividade cognitiva de um sujeito abstrato. É por isso que a epistemologia moderna deve necessariamente meditar sobre Diderot. Sem desordem, não há progresso do saber. O defeito radical do racionalismo é o de querer impor uma ordem que, por definição, contradiz o progresso do saber.

O crescimento da desordem é, assim, a contrapartida do desenvolvimento das ciências. No limite, desenvolvido ao infinito, o saber está morto, já que ele cessa de ser conhecível, equivalendo ao universo ${ }^{19}$. Permitir que a desordem cresça, assim criando a ordem. Representar-se o saber, torná-lo transmissível, sem cair na armadilha do racionalismo e dos sistemas filosóficos. Diderot, desse modo, inventou o primeiro problema filosófico da modernidade, e o resolveu com a Encyclopédie. A solução não consiste em imaginar uma ordem, essa ilusão em que toda a filosofia especulativa descamba, desmentindo o próprio conteúdo do saber. A solução consiste em facilitar a comunicação, em produzir informaçáo sobre o universo cultural; ou seja, dando continuidade à nossa perspectiva, produzir entropia negativa e, consequentemente, ordem. Mercúrio torna-se cúmplice de Dioniso. Pode-se utilizar a razão - quer dizer, o espírito que formou o saber - contra a superstiçáo, sem se deixar prender na filosofia racional. E, se por acaso a coruja de Minerva vier a preferir o crepúsculo às Luzes, é porque ela não é tão genial quanto Saunderson, o cego.

Ora, a história nos mostra que não foi exatamente a solução proposta por Diderot que foi escolhida. Bem pelo contrário, ela foi marginalizada no desenvolvimento da filosofia universitária europeia do século XIX, que se enveredou pela via daquilo que nomeamos, em nossa introdução, de filosofia

18 O artigo "encydopédie" retoma as teses do Da interpretação, insistindo em um tipo de remissão entre os artigos que "nem devem ser abandonados nem refutados completamente", e que "por meio de aproximaçôes audaciosas conduzem a novas verdades especulativas" (pp. 22-23).

19 Ver Da interpretação, VI: "Se o Eterno tivesse cogitado desenhar o mecanismo universal sobre folhas traçadas de sua própria mão, acreditaríamos que esse grande livro seria mais compreensível a nós que o próprio universo?". 
restrita. Diderot foi redescoberto como um objeto de desejo dos literatos, e não de objeto de meditaçôes filosóficas. Pensamos que essa situação é efeito das rupturas que denunciamos no início desta obra. Tais rupturas não nasceram posteriores à obra de Diderot: seu trabalho negativo já estava manifesto na posição ambígua de D’Alembert, aquele que representou o clã dos "filósofos" e que assegurou sua vitória no seio da Academia francesa.

DOI - http://dx.doi.org/10.5902/2179219436596 